\title{
MATERNAL EFFECT ON RESPONSE OF OLEIC ACID CONTENT TO TEMPERATURE IN HIGH OLEIC SUNFLOWER
}

\author{
Ferfuia, C. ${ }^{1}$, Turi, M. ${ }^{2}$, Vannozzi, G.P. ${ }^{1^{*}}$ \\ ${ }^{1}$ Department of Agriculture and Environmental Sciences, \\ University of Udine, via delle Scienze 208, 33100 Udine, Italy \\ ${ }^{2}$ Azienda Agraria Universitaria "A. Servadei", \\ University of Udine, via Pozzuolo 324, 33100 Udine, Italy
}

Received: October 26, 2012 Accepted: December 01, 2012

\begin{abstract}
SUMMARY
High oleic trait has been rarely studied in reciprocal crosses and in most of these cases the maternal effect on the content of unsaturated fatty acids has not been identified. The aims of this study are: i) to check if any maternal effect on oleic acid content is present in high oleic mutants and (ii) if maternal effect and environment conditions could modify the $90 \%$ threshold for oleic acid content. Two high oleic inbred lines with different origins were evaluated: $342 \mathrm{mt}$, a selection derived by Ha 342 USDA (maintainer) and line R978 (male fertility restorer, branched) selected by University of Udine and their reciprocal crosses $(\mathrm{R} 978 \times 342 \mathrm{mt}$ and $342 \mathrm{mt} \times \mathrm{R} 978)$. The two inbred lines respond differently to the same environmental conditions. Reciprocal hybrids showed a different accumulation pattern on the first sowing date, and they showed the same response as their female parent. There is a maternal effect in the early stages of the seed filling phase. Low temperature increased linoleic acid and decreased oleic acid at 13 DAF only in $342 \mathrm{mt}$ inbred line and in the $342 \mathrm{mt} \times \mathrm{R} 978$ hybrid. High oleic inbred lines with different genetic backgrounds respond differently to the same environmental conditions. It was determined that there was the importance of female parental line choices in breeding to obtain hybrids insensitive to environmental conditions and with a stable oleic acid content over $90 \%$. For the first time a maternal effect on temperature response was found in high oleic sunflower.
\end{abstract}

Key words: environment, fatty acids, high oleic genotypes, maternal effect

\section{INTRODUCTION}

High oleic sunflower is currently used in the food sector and as raw material for non food applications (biofuels, oleochemical). Non food applications in particular

* Corresponding author: Phone: +39 0432 558620; Fax:+ 390432 558603;

e-mail: vannozzi@uniud.it 
require oleic acid content that is stable and higher than 90\% (Vannozzi, 2006). In a breeding program targeted to obtain hybrids with an oleic acid content higher than $90 \%$ it is needed to understand all phenomena that modify fatty acids accumulation and their ratio in the seed.

Seed fatty acid composition depends on two factors: the genetic background of the embryo and the female plant condition (abiotic and biotic stresses).

High Oleic (HO) mutants were obtained by chemical mutagenesis, with dimethyl sulfate, of normal sunflowers (Soldatov, 1976). High oleic trait is seed-specific and mutation reduced the expression of a $\Delta 12$-desaturase gene (Lacombe et al., 2004). Its transcript is not accumulated during the grain filling period (Martínez-Rivas et al., 2001). Some linoleic acid is still present in the achenes and it is synthesized by a constitutive desaturase system (Martínez-Rivas et al., 2001; Lagravére et al., 2004).

High oleic trait was controlled by at least three loci: oleHL, supole, and modifier loci (Lacombe et al., 2004). There is variability between HO lines according to the alleles at these different loci. Many genetic approaches have been developed to study the HO mutation and in the literature different conclusions are reported on the number of genes that control the trait and on their dominance.

A small number of studies investigated maternal effect on fatty acids in high oleic sunflower. Only one previous study has reported a maternal effect on high oleic trait (Lacombe and Bervillé, 2000). Reciprocal effects on oleic acid content have been reported by Vares et al. (2004). Maternal effect on fatty acids was also found in other oil crops such as canola and soybean (Thomas and Kondra, 1973; Erickson et al., 1988; Gilsinger et al., 2010).

Oil composition in standard sunflower is clearly affected by the environment. Temperature is a major environmental factor that influences fatty acid composition of the seed. High temperature enhances the oleic acid content of normal cultivars (Low Oleic), but conflicting results are reported about temperature effects on oleic acid content of high oleic acid cultivars: no effect (Lagravére et al., 2000) or increase of oleic acid content with temperature (Triboi et al., 2000; Izquierdo and Aguirrezábal, 2008).

The aims of this study are:

1. to check if any maternal effect on oleic acid content is present in high oleic mutants and

2. if maternal effect and environment could modify the $90 \%$ threshold for oleic acid content.

\section{MATERIALS AND METHODS}

\section{Plant materials}

Two high oleic inbred lines with different origin and their reciprocal cross were used. The inbred lines were: $342 \mathrm{mt}$ and R978. Line $342 \mathrm{mt}$ is a selection derived by Ha 342 USDA, and it is a male sterility maintainer with a single head. Line R978, 
selected by University of Udine, is a fully branched type and it is a male fertility restorer. Reciprocal cross ( $\mathrm{F}_{1}$ seeds) was obtained by hand demasculation of female parent and controlled pollination in field conditions at Udine in 2010. All plants were covered with paper bags during the R4 stage (Schneiter and Miller, 1981) to prevent cross-fertilization. The reciprocal $F_{1}$ seed was planted in the field in 2011 and tested with the parents.

\section{Field experiment}

Inbred lines and their reciprocal hybrids ( $F_{1}$ hybrids plants) were grown in 2011 at the University of Udine, Azienda Agraria Universitaria "A. Servadei" ( $46^{\circ} 04^{\prime} \mathrm{N}, 13^{\circ} 22^{\prime} \mathrm{E}$, altitude $109 \mathrm{~m}$ ). The experiment was designed as a complete randomization scheme with three replications using two dates of sowing. The first date of sowing was 18 April (I) and the second was 31 May 2011 (II). Plants were thinned after seedling emergence from 10 to 7.5 plants $\mathrm{m}^{-2}$. Nitrogen was applied at $100 \mathrm{~kg} \mathrm{ha}{ }^{-1}$. Weeds and diseases were controlled, and regular watering throughout the experiment ensured that plants were not subjected to water deficit during the entire growth period. All plants were covered with paper bags at the R4 stage to prevent cross-fertilization.

\section{Sampling}

Two types of samples were taken: i) 5 seeds per plant; ii) pieces of sunflower head (see below). Seeds samplings were started at 13 DAF (Days After Flowering). Five seeds per plant (obtained from outer rings of the head) were taken every 7 days from $13 \mathrm{DAF}$ to $35 \mathrm{DAF}$, in order to determine fatty acid accumulation. Seeds were dried in an oven at $60^{\circ} \mathrm{C}$ for $24 \mathrm{~h}$. The final harvest was done at physiological maturity (R9; Schneiter and Miller, 1981).

\section{Effect of low temperature}

To simulate the physiological conditions of seed lipid synthesis in the plant, portions of sunflower head were collected at 13, 20, 27 and 35 DAF. Portions of head were incubated in the air, in Petri dishes containing water, at $10^{\circ} \mathrm{C}$ for $24 \mathrm{~h}$ (García-Díaz et al., 2002). After the cold treatment, pieces of head were dried in an oven at $70^{\circ} \mathrm{C}$ for $24 \mathrm{~h}$. An index of the ODS (Oleate Desaturase) activity (Green, 1986) was calculated for each sampling using the formula ODS activity index= $\% 18: 2$ / (\%18:2+\%18:1), where \%18:2 and \%18:1 are the percentage of linoleic and oleic fatty acids, respectively. The value of this index is directly proportional to the activity of the enzyme system believed to be responsible for the desaturation of oleic acid (Cherif et al., 1975).

\section{Fatty acids determination}

Fatty acid composition was determined by gas chromatography and every fatty acid was expressed as a percentage of the total fatty acids detected in the oil. A gas 
chromatograph was fitted with a 60 m HP-88 capillary column (Agilent Technologies, USA). Helium was used as the carrier gas, and the injector, detector and oven temperatures were 230,250 and $200^{\circ} \mathrm{C}$, respectively.

\section{Statistical Analysis}

ANOVA (ANalysis Of VAriance) and LSD (Least Significant Distance) test with pvalue adjusted using Bonferroni correction were applied to experimental results to determine the significance of differences among treatments.

\section{RESULTS}

Sowing date effects on duration of cycle and F-PM (Flowering to Physiological Maturity) phase in inbred lines and reciprocal $F_{1}$ plants are shown in Table 1. Later sowing date resulted in a shorter cycle, likely due to environmental differences during plant development. Within sowing date, reciprocal $F_{1}$ plants had equal developmental timing.

Table 1: Genotypes, sowing date, cycle duration, duration of Flowering to Physiological Maturation (F-PM) and mean temperatures from F-PM for field experiments

\begin{tabular}{lcccccc}
\hline \multirow{2}{*}{ Genotype } & \multirow{2}{*}{$\begin{array}{c}\text { Sowing } \\
\text { date }\end{array}$} & Cycle & F-PM & Tmin & Tmean & Tmax \\
\cline { 3 - 7 } & (dd) & $(\mathrm{dd})$ & ${ }^{\circ} \mathrm{C}$ & ${ }^{\circ} \mathrm{C}$ & ${ }^{\circ} \mathrm{C}$ \\
\hline $342 \mathrm{mt}$ & $\mathrm{I}$ & 110 & 41 & 16.2 & 22.4 & 28.7 \\
$\mathrm{R} 978$ & $\mathrm{I}$ & 113 & 41 & 16.1 & 22.5 & 29.0 \\
$342 \mathrm{mt} \times \mathrm{R} 978$ & $\mathrm{I}$ & 123 & 53 & 16.2 & 23.2 & 30.5 \\
$\mathrm{R} 978 \times 342 \mathrm{mt}$ & $\mathrm{I}$ & 123 & 53 & 16.2 & 23.2 & 30.5 \\
$342 \mathrm{mt}$ & $\mathrm{II}$ & 101 & 37 & 16.7 & 23.9 & 31.5 \\
$\mathrm{R} 978$ & $\mathrm{II}$ & 101 & 37 & 16.7 & 23.9 & 31.5 \\
$342 \mathrm{mt} \times \mathrm{R} 978$ & $\mathrm{II}$ & 108 & 42 & 16.7 & 23.8 & 31.4 \\
R978 $\times 342 \mathrm{mt}$ & $\mathrm{II}$ & 109 & 43 & 16.7 & 23.8 & 31.4 \\
\hline
\end{tabular}

ANOVA results for the main and interaction effects of genotype and sowing date on seed fatty acids composition indicated a significant sowing date by genotype interaction effect. There were some differences between the inbred lines and reciprocal hybrids.

Sowing date did not alter the oleic acid concentration in line R978 and in its R978 $\times 342 \mathrm{mt}$ hybrid. On the other hand, sowing date altered the oleic and linoleic acids concentration in line $342 \mathrm{mt}$ and in the $342 \mathrm{mt} \times \mathrm{R} 978$ hybrid (Table 2 ).

We investigated also the variation in saturated fatty acid concentration through sowing date. Palmitic and stearic fatty acids content did not alter oleic acid concentration (Table 2). Reciprocal hybrids were equal for saturated fatty acids content.

The concentration of oleic acid was affected by the concentration of linoleic acid. This was confirmed by the ODS index. On the first sowing date ODS activity was significantly higher than on the second sowing date only in $342 \mathrm{mt}$ and 
$342 \mathrm{mt} \times \mathrm{R} 978$. Reciprocal hybrids were not equal for unsaturated fatty acids content through sowing date.

Table 2: Fatty acids composition (\%) of seed from self-pollinated inbred lines and hybrids. ODS is an adimensional index of oleato desaturase activity. Results are means $\pm \mathrm{SE}$

\begin{tabular}{|c|c|c|c|c|c|c|}
\hline \multirow{2}{*}{ Genotype } & \multirow{2}{*}{$\begin{array}{l}\text { Sowing } \\
\text { date }\end{array}$} & \multicolumn{4}{|c|}{ Fatty acid (\%) } & \multirow[t]{2}{*}{ ODS } \\
\hline & & Palmitic & Stearic & Oleic & Linoleic & \\
\hline $342 \mathrm{mt}$ & $\mathrm{I}$ & $3.54 \pm 0.04 \mathrm{c}$ & $3.05 \pm 0.22 b c$ & $83.99 \pm 0.64 c$ & $9.42 \pm 0.38 a$ & $0.11 \pm 0.006 a$ \\
\hline R978 & I & $3.12 \pm 0.05 c$ & $2.76 \pm 0.36 \mathrm{bc}$ & $91.92 \pm 0.44 a$ & $2.19 \pm 0.21 \mathrm{~cd}$ & $0.02 \pm 0.002 c$ \\
\hline $342 \mathrm{mt} \times \mathrm{R} 978$ & I & $3.57 \pm 0.12 c$ & $3.39 \pm 0.19 a b$ & $88.07 \pm 0.44 b$ & $4.97 \pm 0.28 b$ & $0.05 \pm 0.003 b$ \\
\hline $\mathrm{R} 978 \times 342 \mathrm{mt}$ & I & $4.47 \pm 0.13 b c$ & $3.31 \pm 0.13 a b$ & $90.62 \pm 0.25 a$ & $1.60 \pm 0.01 \mathrm{~cd}$ & $0.02 \pm 0.000 c$ \\
\hline $342 \mathrm{mt}$ & II & $5.21 \pm 0.39 a$ & $4.25 \pm 0.09 a$ & $87.16 \pm 0.41 b$ & $3.39 \pm 0.88 \mathrm{bc}$ & $0.04 \pm 0.011 b c$ \\
\hline R978 & II & $4.87 \pm 0.04 a$ & $2.91 \pm 0.07 b c$ & $90.81 \pm 0.04 a$ & $1.42 \pm 0.04 \mathrm{~cd}$ & $0.02 \pm 0.003 c$ \\
\hline $342 \mathrm{mt} \times \mathrm{R} 978$ & II & $3.86 \pm 0.13 b c$ & $2.61 \pm 0.10 b c$ & $92.35 \pm 0.20 a$ & $1.09 \pm 0.12 d$ & $0.01 \pm 0.000 c$ \\
\hline $\mathrm{R} 978 \times 342 \mathrm{mt}$ & II & $3.76 \pm 0.15 b c$ & $2.19 \pm 0.06 c$ & $91.56 \pm 0.55 a$ & $1.40 \pm 0.23 d$ & $0.02 \pm 0.003 c$ \\
\hline LSD at $5^{\circ}$ & & 0.90 & 0.96 & 2.19 & 1.98 & 0.02 \\
\hline
\end{tabular}

Values followed by the same letter are not significantly different

(LSD at the $5 \%$ level, $p$-value adjustment Bonferroni).

The oleic acid accumulation showed some differences between R978, 342mt and hybrids. R978 and R978 $\times 342 \mathrm{mt}$ showed the same accumulation pattern for both sowing dates. $342 \mathrm{mt}$ and $342 \mathrm{mt} \times \mathrm{R} 978$ showed the same accumulation pattern as the other genotypes within the second sowing date. There were some differences within the first sowing date.

All the genotypes exhibited a synthesis of linoleic acid at early stages (13 DAF), but we reported a difference between the two high oleic inbred lines and among reciprocal hybrids. Line $342 \mathrm{mt}$ presented the highest initial linoleic acid content followed by a rapid decrease. Line R978 presented a lower initial linoleic acid content than $342 \mathrm{mt}$ followed by a rapid decrease.

In $342 \mathrm{mt}$ and in $342 \mathrm{mt} \times \mathrm{R} 978$, the amount of linoleic acid synthesized is higher than in other genotypes. Reciprocal hybrids were not equal for oleic and linoleic fatty acids content at $35 \mathrm{DAF}$ and at physiological maturity (Figure 1). $342 \mathrm{mt} \times \mathrm{R} 978$ hybrid showed a continuous increase of linoleic acid accumulation ( $1.4 \%$ from 35 DAF to PM).

The cold treatment $\left(10^{\circ} \mathrm{C}\right.$ for $\left.24 \mathrm{~h}\right)$ modified the fatty acid composition only at $13 \mathrm{DAF}$ in line $342 \mathrm{mt}$ and $342 \mathrm{mt} \times \mathrm{R} 978$ hybrid (Figure 2). A net increase in linoleic acid content occurred for both sowing dates. The lowest increase was observed in the seeds incubated at $10^{\circ} \mathrm{C}$ on the second sowing date. The cold treatment on line R978 and hybrid R978 $\times 342 \mathrm{mt}$ did not modify oleic and linoleic acid content in the seeds incubated at $10^{\circ} \mathrm{C}$ (Figure 2). 

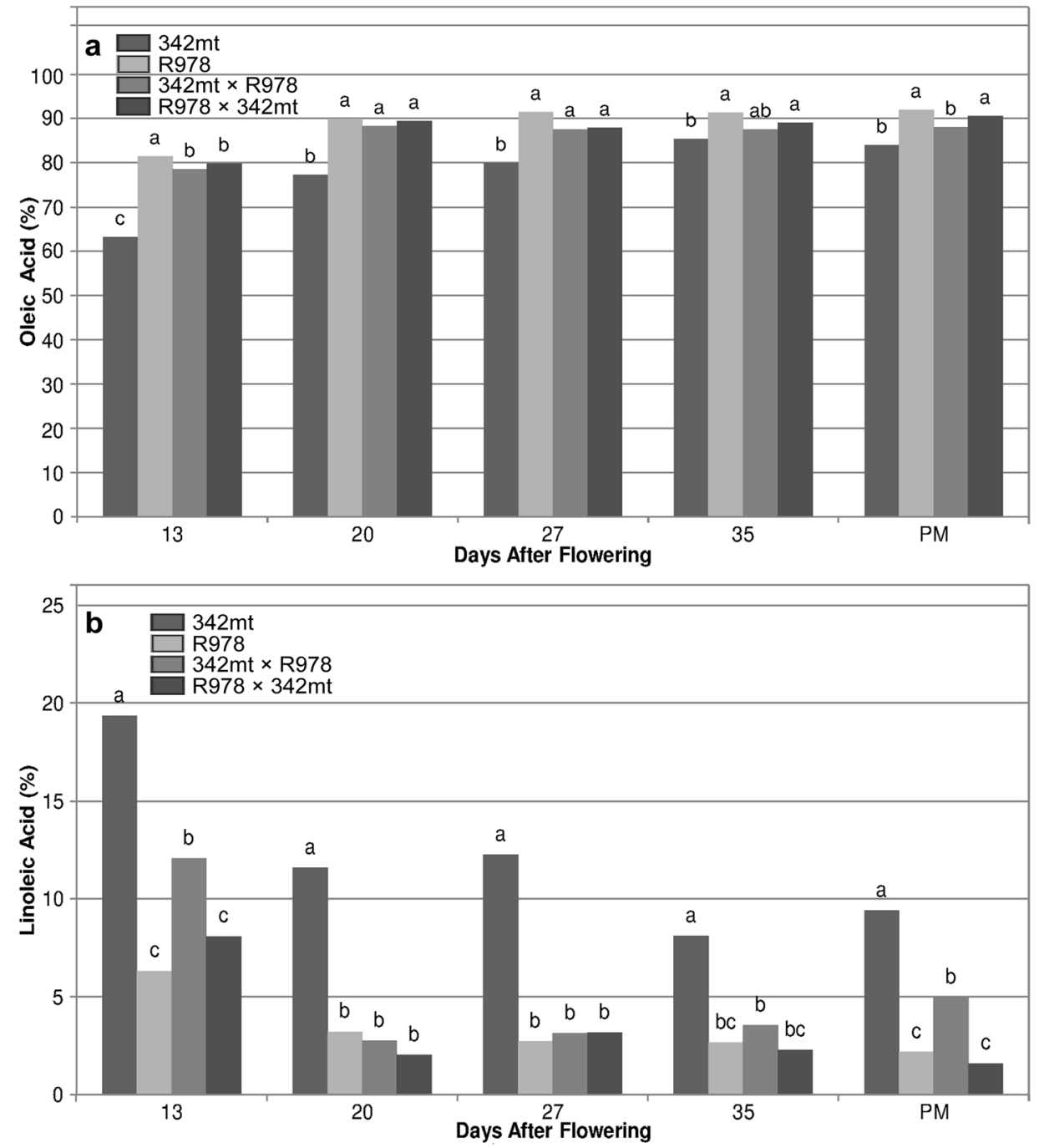

Figure 1: Oleic (a) and linoleic (b) fatty acids accumulation in lines and hybrids on the first sowing date.

\section{DISCUSSION}

The composition of fatty acids showed some difference among inbred lines. Line R978 was insensitive to environment and had the same composition through sowing dates. On the other hand, fatty acids composition in line $342 \mathrm{mt}$ varied through sowing date: oleic acid content increased with temperature (Table 1 and Table 2). Temperature was the main environmental difference among sowing dates; 
other factors that may modify fatty acids composition, such as water and nitrogen, were kept constant. Different genetic background and modifier genes could cause differences between high oleic inbred lines (Lacombe et al., 2004). Thus, some high oleic genotypes showed a response to temperature (Izquierdo and Aguirrezábal, 2008), while others did not (Lacombe and Berville, 2000; Lagravére et al., 2000).
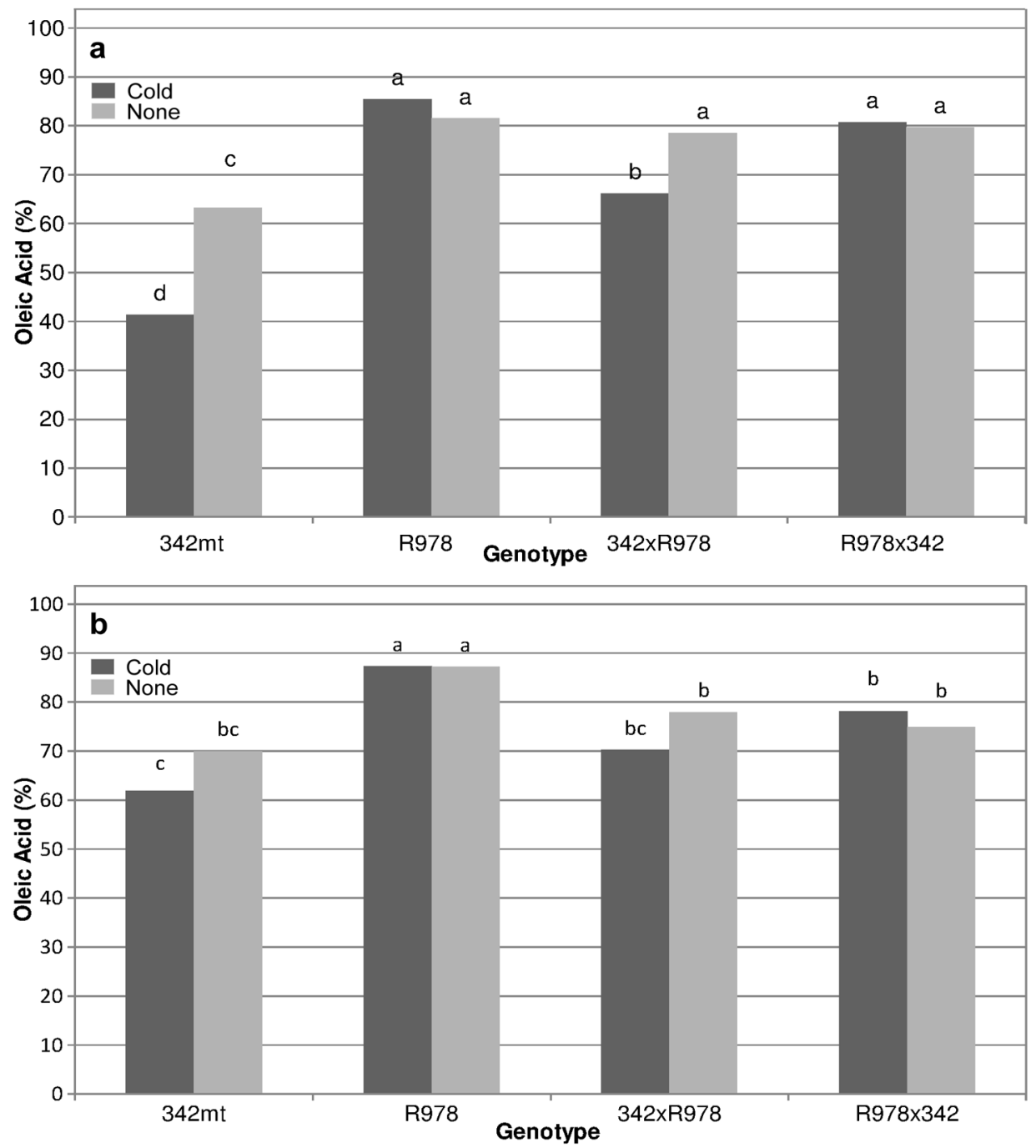

Figure 2: Low temperature $\left(10^{\circ} \mathrm{C}\right)$ effects on oleic acid content at $13 \mathrm{DAF}$ on the first (a) and second sowing date (b).

It seems that difference in oleic acid content at maturity is due to a diverse pattern of fatty acid accumulation and ODS activity and so to different metabolism in high oleic mutants (Figure 1). Different fatty acid metabolism in high oleic hybrids 
was already found by Lagravére et al. (2004). At 13 DAF, line R978 showed an intermediate linoleic content among those reported by Lagravére et al. (2004). According to Martínez-Rivas et al. (2001) and Lagravére et al. (2004), two desaturase systems are involved in the biosynthesis of unsaturated fatty acids. The first one is a constitutive system present in the whole plant, and the second is especially devoted to storage metabolism in the achenes. During the first part of the seed filling period, the constitutive desaturase could be responsible for a low synthesis of linoleic acid in all kinds of hybrids. The specific desaturase is then involved in the accumulation of high quantities of linoleic acid in the standard hybrids, but its activity is lacking in high oleic mutants. We can suppose that $342 \mathrm{mt}$ and R978 are different for constitutive system. In $342 \mathrm{mt}$ there is a constitutive system more active or active for more days than in R978. This is confirmed by low temperature effect. At 13 DAF, R978 did not show any variation in oleic-linoleic ratio, while $342 \mathrm{mt}$ showed a strong response to low temperature (Figure 2). The low temperatureinduced variations in lipid composition at $13 \mathrm{DAF}$ are different between sowing date in line $342 \mathrm{mt}$ and $342 \mathrm{mt} \times \mathrm{R} 978$ hybrid (Figure 2 ). It could be related to the environmental temperature that modifies the activity of the enzyme (Garcés et al., 1992 ) and to a "memory effect" of early temperature regime on the fatty acid desaturation mechanism (Izquierdo et al., 2002). Furthermore, Schlueter et al. (2007) found many oleate desaturase genes in soybean and they reported that some of these genes showed temperature-dependent changes in transcript accumulation in developing pod. A mechanism comparable with soybean may be proposed in sunflower.

Absence of temperature sensitivity from 20 DAF is due to the seeds' age (Garcés et al., 1992).

It seems that temperature response during seed filling phase is related to a maternal effect. The maternal effect, small but significant, on oleic and linoleic acid contents, was detected in reciprocal hybrids plants. The difference was found on response to low temperature at $13 \mathrm{DAF}$ that we assume depends on the constitutive desaturase. Within the second sowing date, environment could mask maternal effect and so reciprocal hybrids are equal. When parents displaying small differences in fatty acid composition are crossed, environment could easily mask any maternal effects (Gilsinger et al., 2010). Different response magnitude between $342 \mathrm{mt}$ and its $342 \mathrm{mt} \times \mathrm{R} 978$ hybrid could be related to a different duration of $\mathrm{F}$ to PM. It is important to note that the magnitude of the maternal effect could be the result of some number of morphological or physiological processes, all of which could be controlled by genes in the nucleus or cytoplasm (Gilsinger et al., 2010).

\section{CONCLUSION}

High oleic inbred lines with different genetic background are not equal for oleic acid content and they show a different genotype by sowing date interaction. Inbred 
line 342mt is sensitive to temperature, while inbred line R978 is not sensitive to temperature. Inbred lines showed a different fatty acid metabolism. An oleate desaturase is active in early seed filling phase in both lines. 342mt showed a greater ODS activity than R978. All this differences depend on different nuclear modifier genes and on maternal effect. For the first time a maternal effect on temperature response was found in high oleic sunflower. Maternal effect could modify oleic acid content and so the $90 \%$ threshold, a goal in a breeding program to develop high oleic hybrids for industrial use.

Further analysis is needed to understand the type of maternal effect and its magnitude in different genetic background and in different environments. We are going to study maternal effects and cytoplasmic inheritance using reciprocal backcrosses. We are going to study reciprocal segregants to obtain information about the persistence of reciprocal differences in later generations.

\section{REFERENCES}

Cherif, A., Dubacq, J., Mache, R., Oursel, A. and Tremolieres, A., 1975. Biosynthesis of alinolenic acid by desaturation of oleic and linoleic acids in several organs of higher and lower plants and in algae. Phytochemistry 14: 703-706.

Erickson, E.A., Wilcox, J.R. and Cavins, J.F., 1988. Fatty acid composition of the oil in reciprocal crosses among soybean mutants. Crop Sci. 28: 644-646.

García-Díaz, M.T., Martínez-Rivas, J.M. and Mancha, M., 2002. Temperature and oxygen regulation of oleate desaturation in developing sunflower (Helianthus annuus) seeds. Physiol. Plant. 114: 13-20.

Garcés, R., Sarmiento, C. and Mancha, M., 1992. Temperature regulation of oleate desaturase in sunflower (Helianthus annuus L.) seeds. Planta 186: 461-465.

Gilsinger, J.J., Burton, J.W. and Carter, T. E. Jr., 2010. Maternal effects on fatty acid composition of soybean seed oil. Crop Sci. 50:1874-1881.

Green, A., 1986. Effect of temperature during seed maturation on the oil composition of lowlinolenic genotypes of flax. Crop Sci. 26: 961-965.

Izquierdo, N. and Aguirrezábal, L., 2008. Genetic variability in the response of fatty acid composition to minimum night temperature during grain filling in sunflower. Field Crop Res. 106: 116-125.

Izquierdo, N., Aguirrezábal, L., Andrade, F. and Pereyra, V., 2002. Night temperature affects fatty acid composition in sunflower oil depending on the hybrid and the phenological stage. Field Crop Res. 77: 115-126.

Lacombe, S. and Bervillé, A., 2000. Problems and goals in studying oil composition variation in sunflower. In: Proc. $15^{\text {th }}$ Int. Sunfl. Conf., Toulouse, France. Int. Sunfl. Assoc., Paris, France. Pp. 1-10.

Lacombe, S., Kaan, F., Griveau, Y. and Bervillé, A., 2004. The Pervenets high oleic mutation: Methodological studies. Helia 27: 41-53.

Lagravére, T., Lacombe, S., Kleiber, D., Bervillé, A. and Dayde, J., 2000. Effects of temperature variations on fatty acid composition in oleic sunflower oil (Helianthus annuus L.) hybrids. In: Proc. $15^{\text {th }}$ Int. Sunfl. Conf., Toulouse, France. Int. Sunfl. Assoc., Paris, France. Pp. A 73-78.

Lagravére, T., Kleiber, D., Surel, O., Calmon, A., Bervillé, A. and Dayde, J., 2004. Comparison of fatty acid metabolism of two oleic and one conventional sunflower hybrids: A new hypothesis. J. Agron. Crop Sci. 190: 223-229.

Martínez-Rivas, J. M., Sperling, P., Lühs, W. and Heinz, E., 2001. Spatial and temporal regulation of three different microsomal oleate desaturase genes (FAD2) from normal-type and higholeic varieties of sunflower (Helianthus annuus L.). Mol. Breeding 8: 159-168.

Schlueter, J.A., Vasylenko-Sanders, I.F., Deshpande, S., Yi, J., Siegfried, M., Roe, B.A., Schlueter, S.D., Scheffler, B.E. and Shoemaker, R.C., 2007. The FAD2 gene family of soybean: 
insights into the structural and functional divergence of a paleopolyploid genome. Crop Sci. 47(S1): S14-S26.

Schneiter, A.A. and Miller, J.F., 1981. Description of sunflower growth stages. Crop Sci. 21: 901-903.

Soldatov, K.I., 1976. Chemical mutagenesis in sunflower breeding. In: Proc. $7^{\text {th }}$ Int. Sunfl. Conf., Krasnodar, USSR. Int. Sunfl. Assoc., Paris, France. Pp. 352-357.

Thomas, P. and Kondra, Z.P., 1973. Maternal effects on the oleic, linoleic, and linolenic acid content of rapeseed oil. Can. J. Plant Sci. 53: 221-225.

Triboi-Blondel, A.-M., Bonnemoy, B., Falcimagne, R., Martignac, M. and Messaoud, J., 2000. The effect of temperature from flowering to maturity on seed composition of high oleic sunflower inbreds and mid oleic hybrids. In: Proc. $15^{\text {th }}$ Int. Sunfl. Conf., Toulouse, France. Int. Sunfl. Assoc., Paris, France. Pp. A 67-72.

Vannozzi, G.P., 2006. The perspectives of use of high oleic sunflower for oleochemistry and energy raws. Helia 29: 1-24.

Varès, D., Lacombe, S., Griveau, Y., Bervillé, A. and Kaan, F., 2004. Inheritance of oleic acid content of $F_{1}$ seed in a complete diallel cross between seven sunflower lines. Helia 25: 105-112. 